\title{
Nano-nutrition of chicken embryos. Effect of gold and taurine nanoparticles on muscle development ${ }^{*}$
}

\author{
M.K. Zielińska ${ }^{1,5}$, E. Sawosz ${ }^{1}$, A. Chwalibog ${ }^{2}$, T. Ostaszewska ${ }^{3}$, \\ M. Kamaszewski ${ }^{3}$, M. Grodzik ${ }^{1}$ and J. Skomial ${ }^{4}$
}

\author{
${ }^{1}$ Warsaw University of Life Sciences, Department of Animal Nutrition and Feed Sciences \\ Ciszewskiego 8, 02-786 Warsaw, Poland \\ ${ }^{2}$ University of Copenhagen, Department of Basic Animal and Veternary Sciences \\ Grønnegårdsvej 3, 1870 Frederiksberg C, Denmark \\ ${ }^{3}$ Warsaw University of Life Sciences, Division of Ichthyobiology and Fisheries \\ Ciszewskiego 8, 02-786 Warsaw, Poland \\ ${ }^{4}$ The Kielanowski Institute of Animal Physiology and Nutrition, Polish Academy of Sciences \\ 05-110 Jabtonna, Poland
}

(Received 15 January 2010; revised version 29 March 2010; accepted 9 May 2010)

\begin{abstract}
The objective of present experiment was to reveal influence of taurine, nanoparticles of gold or nanoparticles of gold conjugated with taurine on molecular and morphological status of muscle's fibre proliferation activity at the end of embryogenesis. The expression of Proliferating Cell Nuclear Antigen (PCNA) was determined in embryonic chicken pectoral muscle using real time PCR and immunohistochemical method. Furthermore, we calculated the average number of nuclei within the muscle fibre fasciculus in cross sectional image. Taurine, supplemented in ovo to chicken embryo, enhanced organization of breast muscle by activating molecular mechanisms evaluated as an expression of PCNA. Nanoparticles of gold did not influence examined parameters.
\end{abstract}

KEY WORDS: chicken embryo, nanoparticles, Au, taurine, muscle, PCNA, hyperplasia

\footnotetext{
* A part of presented results is included in Thesis by Marlena Zielińska This study was partially supported by Polish Ministry of Science and Higher Education, Grant No. MNiSW N311 049 31/3849

${ }^{5}$ Corresponding author: e-mail: zielinska.marlena@gmail.com
} 


\section{INTRODUCTION}

Intensity of poultry selection increased percentage of lean meat, especially mass of breast muscles, but at the same time decreased quality of meat, via enhance hypertrophy of myocytes (Dransfield and Sosnicki, 1999). To prevent this mechanism, scientists try to find methods stimulating increase number of muscles cells, to maintain proper balance between size and number of myocytes. Development during embryogenesis is a crucial period for muscle organization, because during this period number of muscle fibres is nearly completed. During embryogenesis myoblasts proliferate, differentiate into multinucleated myotubes and form muscle fibres, which as a cellular syncitium are enable to further dividing (Velleman et al., 2002). After hatching, only satellite cells, mainly in response to injury, can activate expression of muscle regulatory factors and execute myogenic programme (Kanisicak et al., 2009). The possibility of incorporating of satellite cell nuclei into a muscle fibre may regulate proper balance between hyperplasia and hypertrophy, preventing dystrophy of chicken breast muscles. Activity of satellite cell proliferation, key factor in muscles hypertrophy, is molecular depended mechanism but also influenced by extracellular matrix environment surrounding the cells, composed of collagens, proteoglycanes and glycoproteins (Velleman, 2007). Proteoglycans, mainly glycosaminoglycans (GAG) are responsible for binding growth factors FGF-2 and TGF- $\beta$, necessary to stimulate satellite cell and myoblast (Miura et al., 2006). According to McFarland et al. (2003), expression of FGF2 mRNA is positively correlated with level of heparan sulphate proteoglycans. In fast growing breeds of poultry, scarcity of signaling molecules or their precursors, especially proteins and sulphur-containing compounds can be observed. Nutrition in ovo can provide embryos with nutrients being not adequate for optimal growth and development of embryos and for development after hatching (Uni and Ferket, 2005; Foye et al., 2006).

Taurine can be a donor of sulphur-compounds, being necessary to forming sulphate glycoaminoglycanes, which as a membrane receptors participate in communication between cells (Page, 2000), support cellular nutrion via LDL binding (Lewis i Xu, 2008) and also increase proliferating rate of stem cells (Sasaki et al., 2008). However, when taurine is supplied in ovo, it can be bounded, degraded or stored, becoming unavailable for chicken embryo. Nanoparticles of gold show affinity to - $\mathrm{SH}$ groups and are used as a carrier of sulphur-containing pharmaceutics (Han, 2007). Moreover, Au nanoparticles do not induce inflammatory state (Sawosz et al., 2010) and selectively interact with 
glycoproteins (Mukherjee, 2005), improving organization of connective tissues and blood vessels (Tsai, 2007). It can be hypothesized that taurine as a sulphur donor and/or taurine conjugated with nanoparticles of gold given in ovo can increase number of myocytes prior to hatching, as a consequence of molecular regulation of forming myotubes with satellite cells arrangement.

The objective of presented experiments was to reveal influence of taurine, nanoparticles of gold or nanoparticles of gold conjugated with taurine on molecular and morphological status of the proliferation of muscle's cells activity at the end of embryogenesis.

\section{MATERIAL AND METHODS}

Fertilized eggs $(n=120,66.9 \pm 3.6 \mathrm{~g})$ from Ross Line 308, obtained from commercial hatchery, Dębowka (Poland), were randomly divided into groups: I (control), II (hydrocolloid of Au nanoparticles), III (taurine) and IV (hydrocolloids of Au nanoparticles with taurine). Eggs were incubated at standard conditions (temperature $37.7^{\circ} \mathrm{C}$, humidity $60 \%$, turn once per $\mathrm{h}$ in first 18 days, and later at temperature $37^{\circ} \mathrm{C}$ and humidity $70 \%$ ) in incubator ALMD1N3-7 (F.H.U. Waleński; Gostyn, Poland). Experimental solutions were given in ovo, at 3 days of incubation, by injection $0.5 \mathrm{ml}$ of experimental solution to air sack using $1 \mathrm{ml}$ tuberculin syringe in sterile conditions. After the eggs were injected, the injection holes were sealed with hypoallergic tape, and eggs were placed in the incubator (Grodzik and Sawosz, 2006). Hydrocolloid of $\mathrm{Au}$, produced by non-explosive high voltage patented method from high purity metals and high purity water, was obtained from Nano-Tech, sp. zoo. (Poland). The structure of nanoparticles was visualized using transmission electron microscope (TEM) JEOL model JEM-2000EX. Taurine (Sigma Aldrich) was dissolved in mili-Q water at a concentration of $4.32 \mathrm{mg} / \mathrm{ml}$. Hydrocolloid of $\mathrm{Au}$ nanoparticles conjugated with taurine was prepared by sonification during $30 \mathrm{~min}$ at temperature $37^{\circ} \mathrm{C}$ in ultrasonic cleaning (Sonorex Super RK 514H, BANDELIN). After 20 days of incubation eggs were taken from the incubator, opened and embryos were sacrificed by decapitation and immediately samples of muscles were pull in RNAlater Tissue Collection: RNA Stabilization Solution (Ambion Inc.) and stored at $8^{\circ} \mathrm{C}$ for PCR Real Time analyses.

RNA was isolated using the SV Total RNA Isolation System (Promega) according to the manufacturer's protocol. It was translated into cDNA using both random hexamer priming as well as oligo(dT), and the product of these 
reactions were mixed. The PCR primer oligonucleotide was designed from chicken mRNA sequences for PCNA and PCR conditions were optimized on chicken muscle cDNA samples. The primer produced amplification of the expected band on muscle cDNA samples from control chicken embryos and of larger size on chicken genomic DNA. Quantifying of enzyme cDNA levels was subsequently done by real time PCR using SYBR Green I detection and the LightCycler System (Roche Diagnostics). For each sample, $160 \mathrm{ng}$ of cDNA template was added to $5 \mu 1$ of SyBR green master mix (Roche Diagnostics) and $1 \mu \mathrm{l}$ of both forward and reverse primer (final concentration of $1 \mu \mathrm{M}$ each) was added to a total volume of $10 \mu 1$ with RNA-free water. An initial denaturing step at $95^{\circ} \mathrm{C}$ for 5 min was followed by 45 cycles with a denaturing step at $95^{\circ} \mathrm{C}$ (10s), an annealing step at $60 / 62^{\circ} \mathrm{C}(10 \mathrm{~s})$ and an elongation step at $72^{\circ} \mathrm{C}(10 \mathrm{~s})$. Beta-actin was used as reference gene. For analysis, cycling reports and melting curves were evaluated. All the reactions were done in triplicate.

For immunohistochemical analyses pectoral muscle from 6 individuals was studied. The tissues were fixed in Bouin's solution embedded in Paraplast (Sigma Aldrich). They were cut into transversal slices of $5 \mu \mathrm{m}$ thickness using a microtome (Leica RM 2265, Leica Microsystems). Tissue sections were dewaxed with xylene and rehydrated. Endogenous peroxidase was blocked with a $3 \%$ solution of $\mathrm{H}_{2} \mathrm{O}_{2}$. Immunohistochemical analyses were performed using EnVision+ System-HRP (DAB) used for Mouse Primary Antibodies (DAKO) according to the procedures described by the manufacturer. Proliferating nuclei cells were identified via immunohistochemistry using monoclonal mouse antichicken antibodies at a 1:50 dilution (IMGENEX) directed against PCNA. The sections were incubated with the primary antibodies for $1 \mathrm{~h}$ at room temperature and then incubated with 3.3'-diaminobenzidine (DAB)+ substrate-chromogen (DAKO kit), resulting in a brown-coloured precipitate at the antigen site. The number of PCNA-positive nuclei was estimated as percent of PCNA-positive cells to the total cell number (\% PCNA positive cells/total cells). Furthermore, the ratio of PCNA-positive nuclei to the total number of counted nuclei, within one fasciculus of muscle fibres, was counted, usingcross sectional image of pectoral muscle.

The data were analysed using two-factorial analysis of variance ANOVA and the differences between groups were tested by the multiple range Duncan test, using Statgraphics Plus 4.1. Differences with $\mathrm{P}<0.05$ were considered significant. 


\section{RESULTS}

The present results indicated that gene expression of PCNA at mRNA level was lower in the breast muscles of embryos supplemented in ovo with taurine (Table 1). The supplement of Au nanoparticles had no effect on PCNA expression and also there was no interaction between taurine and $\mathrm{Au}$ supplementation. Immunohistochemical measurements showed that the ratio of PCNA-positive nuclei to the total number of counted nuclei, within one fasciculus of muscle fibres, carried out in cross-sectional image of pectoral muscle, was higher in taurine groups (Table 1). The gold nanoparticles injected in ovo did not influence percentage of PCNA-positive nuclei, as well as the interaction between $\mathrm{Au}$ nanoparticles and taurine was not significant. The average number of nuclei within the muscle fibre fasciculus in cross sectional image was higher in group with taurine (Table 1), but there was no significant differences between groups.

Table 1. Results of PCNA at mRNA level gene expression (PCR Real Time) in pectoral muscle, \% PCNA positive cells in total cells (immunochemistry) and the average number of nuclei $/ \mathrm{mm}^{3}$ within the muscle fibre fasciculus in cross sectional image (immunochemistry)

\begin{tabular}{|c|c|c|c|c|c|c|c|c|c|c|}
\hline \multirow{4}{*}{ Factor } & \multirow{2}{*}{\multicolumn{2}{|c|}{ Without taurine }} & \multirow{2}{*}{\multicolumn{2}{|c|}{ Taurine }} & \multicolumn{5}{|c|}{ ANOVA } & \multirow{4}{*}{$\begin{array}{c}\mathrm{Au} \mathrm{x} \\
\text { taurine }\end{array}$} \\
\hline & & & & & \multirow{3}{*}{ SEM } & \multicolumn{4}{|c|}{ effect of } & \\
\hline & \multirow{2}{*}{-} & \multirow{2}{*}{$\mathrm{Au}$} & \multirow{2}{*}{-} & \multirow{2}{*}{$\mathrm{Au}$} & & \multicolumn{2}{|c|}{$\mathrm{Au}$} & \multicolumn{2}{|c|}{ taurine } & \\
\hline & & & & & & SEM & $\mathrm{P}$ & SEM & $\mathrm{P}$ & \\
\hline \multicolumn{11}{|c|}{ mRNA expression, normalized ratio to reference gene $\beta$-actin } \\
\hline PCNA & 3.2683 & 3.6008 & 0.9868 & 1.0125 & 0.7135 & 0.5045 & 0.81 & 0.5045 & 0.003 & 0.84 \\
\hline \multicolumn{11}{|c|}{ Protein expression, \%PCNA positive cells/total cells } \\
\hline PCNA & 0.4024 & 0.4784 & 0.5756 & 0.5547 & 0.3740 & 0.0264 & 0.47 & 0.0264 & 0.003 & 0.21 \\
\hline \multicolumn{11}{|c|}{ The average number of nuclei within the muscle fibre fasciculus in cross sectional image } \\
\hline PCNA & 21781 & 20589 & 27096 & 26888 & 1526.2 & 1079.2 & 0.65 & 1079.2 & 0.0011 & 0.75 \\
\hline
\end{tabular}

\section{DISCUSSION}

The chicken embryo has been chosen as an animal model, being independent from external nutrient and water supply, thus comprising a system being directly dependent on in ovo provision of experimental compounds. State of chicken embryo muscle's fibres, at 20 day of embryogenesis, is almost finally organized structure, resulting from information carried by DNA but depending on nutritional factors. Taurine, given in ovo, increased number of muscle nuclei 


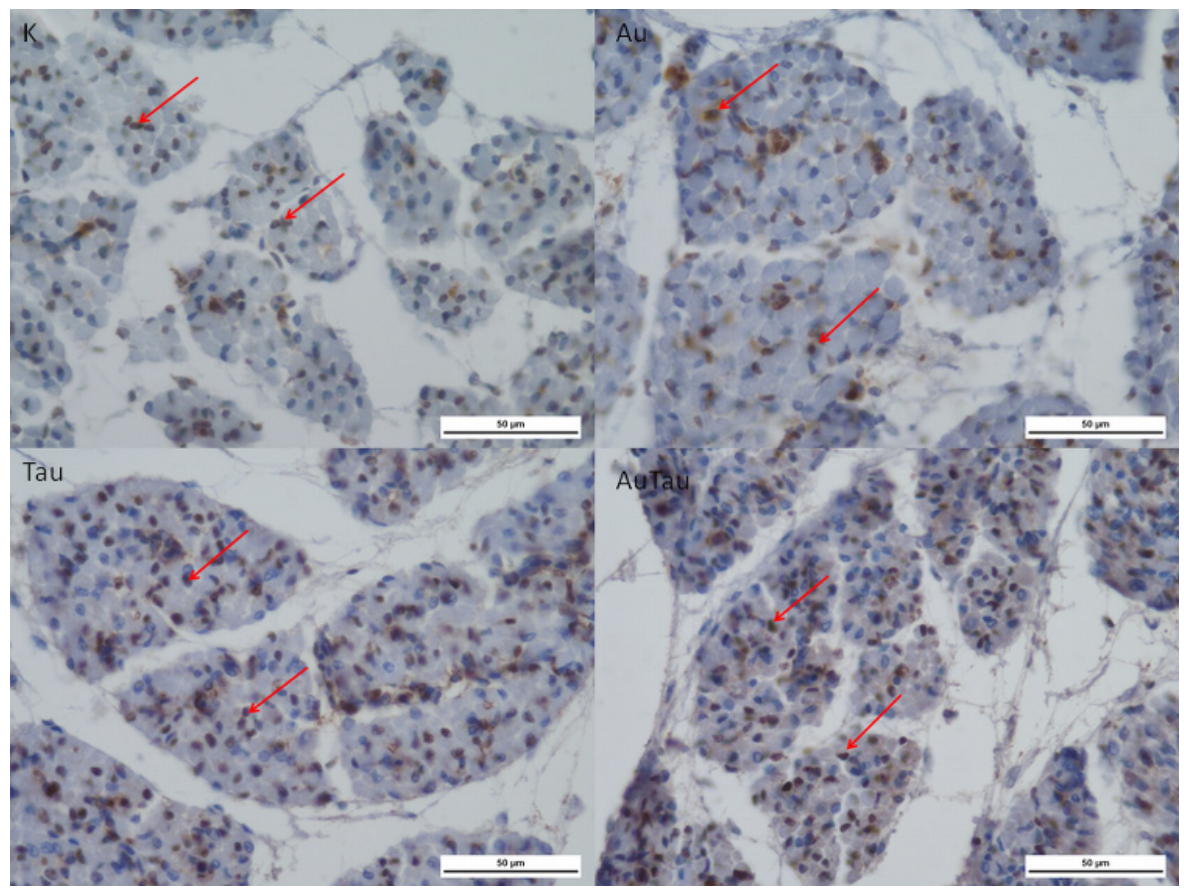

Figure 1. Immunostaining images for PCNA in chicken embryos' pectoral muscle in crosssection view for groups: $\mathrm{K}$ - control (without $\mathrm{Ag}$ and taurine), $\mathrm{Au}$ - injected with Au nanoparticles, Tau - injected with taurine, AuTau - injected with Au nanoparticle-taurine complex. PCNA positive nuclei are brown (arrows) and negative nuclei are blue

of 20 day old chicken embryo, indicating scarcity of taurine in fast growing organism of modern fast growing chickens. Moreover, our other experiments (unpublished) showed that another source of sulphur - heparan sulphate, given in ovo increased number of muscle nuclei. Heparan sulphate can form a complex with FGF2 and vascular endothelium receptor, key regulators of muscles development, but loss of sulphur groups block its activity (Casu et al., 2004). Consequently, it can be suspected that the store of sulphur-containing compounds, within eggs, in fast growing chickens can be insufficient to fulfil their genetic potential.

To recognize molecular mechanism of increasing number of muscle's nuclei, proliferating cells were identified via immunohistochemistry, using antibodies directed against Proliferating Cell Nuclear Antigen. Analysis of cell cycle regulatory proteins pointed out that levels of PCNA are excellent markers of cell proliferation state (Johnson, 1993). PCNA - a protein molecule, 
which is found in nucleus, is involved in DNA polymerase $\delta$ and polymerase $\varepsilon$ regulation. Maximal concentration of PCNA protein is observed in nucleus during the interphase of cell cycle $(\mathrm{G} 1, \mathrm{~S}, \mathrm{G} 2)$ and it is declining during the division of cells and during $\mathrm{G}_{0}$ phase (Paunesku, 2001). Present results showed increase of percentage of PCNA-positive cells in chicken embryo breasts muscle treated with taurine, indicating that bigger amount of muscle cells were present within interphase. Myocytes are multinuclear fibres, which result from fusion of myoblasts being in the post-mitotic G1 phase (Bischoff and Holtzer, 1969). Furthermore, expression of PCNA is a proper marker of anenter of satellite cells, which are also precursors of muscle's fibres, into $\mathrm{S}$ phase of cell cycle (Johnson, 1993). Assuming that an increase of PCNA positive cells in the muscles reflects state when more cells are involved in non-dividing structure of myotubes, this may suggest improved balance between hypertrophy to hyperplasia in chicken after hatching.

In the present experiment reduced expression of PCNA mRNA in pectoral muscle of chicken embryo at 20 day of incubation was determined. We can suspect that down regulation mechanism could be a reason of this phenomenon. Higher concentration of protein can decline gene expression, being a mechanism which protects cells against over-activity of proliferation process (Kelman, 1997). On the other hand, in the present experiment the measurements took place at the end of embryogenesis when hyperplasia is completed and satellite cells conquest control of muscles fibre regeneration as a potential stem muscles cells (Morgan and Partridge, 2003). Decreased mRNA expression of PCNA can be involved in process of preparing ability of satellite cells to divide, considering that the activation of satellite cell proliferation is critical during muscle hypertrophy (Mozdziak et al., 2002). However, further studies are required to explain present results.

It is interesting to note that in the present experiment gold nanoparticles, added alone or conjugated with taurine, did not affect muscle development at a molecular level, suggesting their potential applicability as carriers of nutrients has to be re-evaluated. Nevertheless, effects of gold nanoparticles on postnatal development and product quality ought to be investigated as well.

\section{CONCLUSIONS}

Taurine, supplemented in ovo to chicken embryo, enhanced organization of breast muscle by increasing number of muscles cells, by activating molecular mechanisms evaluated as expression of PCNA. Nanoparticles of gold did not influence examined parameters. 


\section{REFERENCES}

Bischoff R., Holtzer H., 1969. Mitosis and processes of differentiation of myogenic cells in vitro. J. Cell Biol. 41, 188-200

Casu B., Guerrini M., Torri G., 2004. Structural and conformational aspects of the anticoagulant and anti-thrombotic activity of heparin and dermatan sulfate. Curr. Pharm. Des. 10, 939-949

Dransfield E., Sosnicki A.A., 1999. Relationship between muscle growth and poultry meat quality. Poultry Sci. 78, 743-746

Foye O.T., Uni Z., Ferket P.R., 2006. Effect of in ovo feeding egg white protein, beta-hydroxy-betamethylbutyrate, and carbohydrates on glycogen status and neonatal growth of turkeys. Poultry Sci. 85, 1185-1192

Grodzik M., Sawosz E., 2006. The influence of silver nanoparticles on chick embryo development and bursa fabricius morphology. J. Anim. Feed Sci. 15, Suppl. 1, 111-115

Han G., Ghosh P., De M., Rotello V.M., 2007. Drug and Gene Delivery using Gold Nanoparticles. Nano Bio Technol. 3, 40-45

Johnson S.E., Allen R.E., 1993. Proliferating cell nuclear antigen (PCNA) is expressed in activated rat skeletal muscle satellite cells. J. Cell Physiol. 154, 39-43

Kanisicak O., Mendez J.J., Yamamoto S., Yamamoto M., Goldhamer D.J., 2009. Progenitors of skeletal muscle satellite cells express the muscle determination gene, MyoD. Dev. Biol. 332, 131-134

Kelman Z., 1997. PCNA: structure, functions and interactions. Oncogene 14, 629-640

Lewis E.J., Xu X., 2008. Abnormal glomerular permeability characteristics in diabetic nephropathy. Diabetes Care 31, 202-207

McFarland D.C., Liu X., Velleman S.G., Caiyun Z., Coy C.S., Pesall J.E., 2003. Variation in fibroblast growth factor response and heparan sulfate proteoglycan production in satellite cell populations. Comp. Biochem. Physiol. Pt C 134, 341-351

Miura T., Kishioka Y., Wakamatsu J., Hattori A., Hennebry A., Berry C.J., Sharam M., Kambadur R., Nishimura T., 2006. Decorin binds myostatin and modulates its activity to muscle cells. Biochem. Biophys. Res. Commun. 340, 675-680

Morgan J.E., Partridge T.A., 2003. Muscle satellite cells. Int. J. Biochem. Cell Biol. 35, 1151-1156

Mozdziak P.E., Walsh T.J., McCoy D.W., 2002. The effect of early posthatch nutrition on satellite cell mitotic activity. Poultry Sci. 81, 1703-1708

Mukherjee P., Bhattacharya R., Wang P., Wang L., Basu S., Nagy J.A., Atala A., Mukhopadhyay D., Soker S., 2005. Antiangiogenic properties of gold nanoparticles. Clin. Cancer Res. 11, 35303534

Page C., 2000. The role of proteoglycans in the regulation of airways inflammation and airways remodelling. J. Allerg. Clin. Immunol. 105, S518-21

Paunesku T., Mittal S., Protic M., Oryhon J., Korolev S.V., Joachimiak A., Woloschak G.E., 2001. Proliferating cell nuclear antigen (PCNA): ringmaster of the genome. Int. J. Radiat. Biol. 77, $1007-1021$

Sasaki N., Okishio K., Ui-Tei K., Sago K., Kinoshita-Toyoda K., Hidenao Toyota T., Nishimura K., Suda A., Hayasaka M., Hanaka K., Seiji Hitoshi S., Ikenaka K., Nishihara S., 2008. Heparan sulfate regulates self-renewal and pluripotency of embryonic stem cells. J. Biol. Chem. 283, 3594-3606

Sawosz E., Grodzik M., Lisowski P., Zwierzchowski L., Niemiec T., Zielińska M., Szmidt M., Chwalibog A., 2010. Influence of hydrocolloids of $\mathrm{Ag}, \mathrm{Au}$, and $\mathrm{Ag} / \mathrm{Cualloy}$ nanoparticles on the inflammatory state at transcriptional level. Bull. Vet. Inst. Pulawy 54, 81-85 
Tsai C.Y., Shiau A.L., Chen S.Y., Chen Y.H., Cheng P.C., Chang M.Y., Chen D.H., Chou C.H., Wang C.R., Wu C.L., 2007. Amelioration of collagen-induced arthritis in rats by nanogold. Arthritis Rheum. 56, 544-554

Uni Z., Ferket P.R., Tako E., Kedar O., 2005. In ovo feeding improves energy status of late-term chicken embryos. Poultry Sci. 84, 764-770

Velleman S.G., 2002. Role of the extracellular matrix in muscle growth and development. J. Anim. Sci. 80, Suppl. 2, E8-E13

Velleman S.G., 2007. Muscle development in the embryo and hatchling. Poultry Sci. 86, 10501054 